\title{
Personality differences and COVID-19: are extroversion and conscientiousness personality traits associated with engagement with containment measures?
}

\author{
Lucas de F. Carvalho, ${ }^{1}$ (D) Giselle Pianowski, ${ }^{1}$ (D) André P. Gonçalves ${ }^{1}$ (D)
}

\begin{abstract}
Introduction: In December 2019, an outbreak of the novel coronavirus, the coronavirus disease 2019 (COVID-19) probably occurred in Wuhan, China. By March 2020, the World Health Organization (WHO) had declared a pandemic. Containment measures such as social distancing and hand hygiene were recommended. In this study, we start from the hypothesis that engaging with containment measures in a pandemic situation should be more comfortable for some people than for other people. Thus, individual differences should be associated with engagement with containment measures.

Objective: To investigate to what extent two personality traits, extroversion and conscientiousness, are associated with engagement with two containment measures (social distancing and handwashing).

Methods: The sample consisted of 715 Brazilian adults aged 18-78 years, who answered the Big Five Inventory 2 Short (BFI-2-S) and factors from the Dimensional Clinical Personality Inventory 2 (IDCP-2). Results: Higher scores for extroversion were associated with lower means for social distancing ( $p<$ 0.001 ) and higher scores for conscientiousness were associated with higher means for social distancing and handwashing $(p<0.05)$.

Conclusion: The findings indicate the importance of acknowledging extroversion and conscientiousness traits as relevant to people's engagement with the measures recommended for COVID-19 containment. Keywords: SARS-CoV-2, disease outbreaks, personality; extraversion, perfectionism.
\end{abstract}

\section{Introduction}

In December 2019, cases of life-threatening pneumonia were reported in Wuhan, China, catching the attention of the international audience. The number of reported cases increased rapidly in Wuhan and other Chinese cities. Cases were also diagnosed in other parts of the world. The source of the outbreak of this novel coronavirus, the coronavirus disease 2019 (COVID-19), is believed to be related to live animal markets selling wild and domestic animals in proximity to large cities with high levels of human density. On January 30, 2020, the World Health Organization (WHO) declared that COVID-19 constituted a Public Health Emergency of International Concern. By March 19, 2020 , within a matter of 3 months since the beginning of the outbreak and about one week after the WHO had officially declared a pandemic, more than 240,000 confirmed cases of COVID19 had been announced and almost 10,000 deaths had been registered, mostly in Italy and China. Outside of these, 176 countries had reported more than 130,000 cases. Unfortunately, as we write this paper, the COVID-19 emergency is evolving rapidly. ${ }^{1-3}$

Similar to other coronaviruses (e.g., MERS-COV), ${ }^{4}$ the negative impact of COVID-19 and its consequences

${ }^{1}$ Universidade São Francisco, Campinas, SP, Brazil.

Submitted Mar 21 2020, accepted for publication Mar 312020.

Suggested citation: Carvalho LF, Pianowski G, Gonçalvez AP. Personality differences and COVID-19: are extroversion and conscientiousness personality traits associated with engagement with containment measures? Trends Psychiatry Psychother. 2020;42(2):179-184. http://dx.doi.org/10.1590/2237-6089-20200029 
are vast, including negative outcomes in mental health, with increased depressive and anxiety symptoms, stress disorders, insomnia, anger, and fear. ${ }^{5-10}$ Furthermore, pandemics are known to provoke social disruptions. ${ }^{1,2}$

Several publications warned of the need for containment measures, ${ }^{11-15}$ mostly focusing on social distancing (defined as a set of actions aimed to stop or slow down the spread of a contagious disease, such as maintaining distance from other people and avoiding leaving the home) ${ }^{16}$ and hand hygiene (including handwashing with soap and water, and hand sanitizing with alcoholic solutions). Although lacking empirical evidence, previous publications have argued that habits and behavioral trends (e.g., partying hard, not following norms) have impacts on containment measures, ${ }^{17,18}$ stressing that individual behavior is crucial to controlling the spread of COVID-19.

Li et al. ${ }^{19}$ conducted a study in China ( $n=4,607$ ) investigating the impact of people's behavior on COVID-19 containment measures. The authors focused on social participation, precautionary behavior, and perceived severity, among other behaviors. Findings indicated that people are tending to avoid social events since the outbreak of COVID-19, to exhibit precautionary behaviors such as wearing a facemask and washing hands, and to perceive the impacts of COVID-19 as highly negative (e.g., high mortality and negative influence on social order and economics). We can therefore observe some initial results indicating that people are inclined to adhere to containment measures in extreme situations. A necessary further step is to investigate the role of individual differences in the propensity to adhere to containment measures, which is the scope of our study.

In this study, we start from the assumption that engaging with containment measures in a pandemic situation should be easier for some people than others. Individual differences are expected to be associated with the disposition to engage in these measures. We aimed to investigate associations between two personality traits, extroversion and conscientiousness, and engagement with two containment measures (social distancing and handwashing). Therefore, we used the Five-Factor Model (FFM) as the framework for personality traits, since it is the model closest to the scientific consensus. ${ }^{20}$ The FFM proposes that personality is best described in five broad traits: extroversion (or extraversion), agreeableness, conscientiousness, neuroticism, and openness. A personality trait is a stable psychological characteristic that contributes to determining how people experience the world as well as to the impact of these experiences. ${ }^{21}$ Our focus is on the extroversion trait, since people who score high for this trait are outgoing and generally prone to closeness and social contact; and on conscientiousness, since people who score high for this trait are organized, meticulous, and tend to respect norms and social rules. We hypothesize that extroverted people are less likely to engage with the COVID-19 pandemic containment measures than highly conscientious people.

\section{Methods}

This is a cross-sectional study, nested within a larger mental health project in Brazil, with research ethics committee approval (CAAE: 09112419.7.0000.5514). All participants signed an informed consent form before participating.

\section{Participants}

The study sample consisted of 715 Brazilian adults, recruited by convenience between March 18 and 19 of 2020. The sole eligibility criterion was age $\geq 18$ years.

\section{Measures}

Questionnaire on COVID-19-related behavior

We developed a questionnaire to measure general information and behavior-related to the COVID-19 pandemic situation. Focusing on our objective, we selected two variables associated with containment measures, specifically, social distancing and handwashing behaviors. We presented participants with "yes or no" response format questions, "Do you think it is necessary to avoid approaching people as much as possible until the coronavirus situation is controlled?" and "Do you think it is necessary to wash your hands and/or use alcohol gel as many times a day as possible until the coronavirus situation is controlled?".

\section{Big Five Inventory-2 Short (BFI-2-S) ${ }^{22}$}

The BFI-2-S is a self-report measure of personality traits based on the FFM, evaluating extroversion, agreeableness, conscientiousness, neuroticism, and openness. This measure is composed of 30 items that are answered on a 5-point Likert scale. Psychometric investigations of the BFI-2-S in Brazil have not yet been published, although the Ayrton Senna Institute has published documents regarding the previous version of the BFI-2-S. ${ }^{23}$ Prior evidence suggests the BFI-2-S has good psychometric properties and indicates strong correlations between the BFI- 2 and the BFI. ${ }^{22}$

Dimensional Clinical Personality Inventory 2 (IDCP-2) ${ }^{24}$

The IDCP-2 was developed in Brazil and is a selfreport measure that assesses pathological traits, i.e., extreme maladaptive variants of personality traits. 
It is composed of 206 items answered on a 4-point Likert scale. The IDCP-2 encompasses 47 factors. In this study, we administered four factors, two related to extroversion, Need for attention and Intimacy avoidance (negatively related), and two related to conscientiousness, Thoroughness and Concern with details. Studies support the psychometric properties of this measure, including studies focused on the factors we administered (e.g., Carvalho et al. ${ }^{25,26}$ ).

\section{Procedure}

After approval by the São Francisco University research ethics committee, data collection was performed online via Google Forms. We shared the research link on the social media website Facebook and via the WhatsApp app, inviting individuals to participate and relying on the snowball strategy to reach a larger number of participants. For both Extroversion and Conscientiousness dimensions, we administered measures on healthy and maladaptive variant levels of personality, using the BFI-2-S and IDCP-2 respectively; and administered a questionnaire focusing on COVID19-related behavior.

\section{Data analysis}

We divided participants into four groups: None $=$ people who think that containment measures are not important $(n=6)$; Social distancing = people who think social distancing is important, but handwashing is not ( $\mathrm{n}$ = 17); Handwashing = people who think handwashing is important, but social distancing is not $(n=23)$; and All = people who think that all containment measures are important ( $n=669$ ). We conducted analysis of variance (ANOVA) with a post hoc test (Tukey method) to compare groups by personality measures. We applied the bootstrapping procedure because the groups' sizes varied widely. We used 0.05 as the significance level, and partial eta squared was used as an indicator of effect size. We performed the analysis using SPSS version 23 .

\section{Results}

Table 1 reports descriptive statistics for basic sociodemographic data and specific information related to COVID-19.

Table 1 - Sociodemographic data and COVID-19-related information

\begin{tabular}{lcc}
\hline Variable & Mean (SD) & Min-max \\
\hline Age & $34.1(11.6)$ & $18-78$ \\
\cline { 2 - 3 } & Raw & $\%$ \\
\cline { 2 - 3 } Sex & & \\
Female & 553 & 162 \\
Male & 77.3 & 22.7 \\
Educational level & & \\
Elementary & & \\
High School & 4 & 0.6 \\
College student & 54 & 7.6 \\
Graduate & 165 & 23.1 \\
Postgraduate & 206 & 28.8 \\
Region of Brazil & 286 & 40 \\
South & & \\
Southwest & & \\
North & 18 & 2.5 \\
Northeast & 485 & 67.8 \\
Mid-west & 11 & 1.5 \\
Ethnicity & 157 & 22 \\
Caucasian & 44 & 6.2 \\
Brown & & \\
Black & & \\
Asian & & \\
Other & 497 & 69.5 \\
\hline & 161 & 22.5 \\
\hline
\end{tabular}

\begin{tabular}{lcc}
\hline Variable & Raw & \% \\
\hline Marital status & 373 & 52.2 \\
Single & 297 & 41.5 \\
Married & 32 & 4.5 \\
Divorced & 6 & 0.8 \\
Widowed & 7 & 1 \\
Other & & \\
Medical conditions & 118 & 16.5 \\
Chronic respiratory & 83 & 11.6 \\
Cardiovascular & 18 & 2.5 \\
Diabetes & 5 & 0.7 \\
Renal insufficiency & 2 & 0.3 \\
Cancer & & \\
Tested for CoviD-19 & & \\
No & 710 & 99.3 \\
Yes, negative & 3 & 0.4 \\
Yes, positive & 2 & 0.3 \\
Know someone tested for COVID-19? & & \\
No & 627 & 87.7 \\
Yes, negative & 63 & 8.8 \\
Yes, positive & 25 & 3.5 \\
Had symptoms in last two weeks? & & \\
No & 664 & 92.9 \\
Yes & 51 & 7.1 \\
\hline
\end{tabular}

$\mathrm{SD}=$ standard deviation. 
The total number of participants was 715 adults, mostly female $(77.3 \%)$, single $(52.2 \%)$, Caucasian $(69.5 \%)$, and holding post-graduate degrees (40\%). All pre-existing medical conditions related to increased risk of death from COVID-19 were reported by at least one participant. Two participants from the Southwest region reported being positive for COVID-19, and 25 (14 from the Southwest, six from the Mid-west, and five from the Northeast) reported knowing someone positive for COVID-19. Table 2 presents the results of the ANOVA.
We see a trend towards lower extroversion scores in the social distance group ( $p<0.001)$, indicating that people who are more concerned with social distance tend to be less extroverted. We also observe a trend to lower conscientiousness scores for the groups that considered neither of the containment measures were essential in the current pandemic situation ( $p=0.011)$. When compared to extroversion, we observe higher means for conscientiousness in the groups of people who reported adhering to both or one of the containment

Table 2 - ANOVA comparison of groups by engagement with containment measures.

\begin{tabular}{|c|c|c|c|c|c|c|c|c|}
\hline Measures/groups & $\mathbf{M}$ & M lower & M upper & SD & $\mathbf{F}$ & df & $\mathbf{p}$ & Partial $n^{2}$ \\
\hline \multicolumn{9}{|l|}{ Extroversion } \\
\hline \multicolumn{9}{|c|}{ Extroversion (BFI-2-S) } \\
\hline None & 3.02 & 27.50 & 33.33 & 0.37 & & & & \\
\hline Social distancing & 2.80 & 2.45 & 3.16 & 0.76 & & & & \\
\hline Handwashing & 3.48 & 3.27 & 3.69 & 0.48 & & & & \\
\hline All & 3.42 & 3.37 & 3.47 & 0.64 & 5.98 & 3 & 0.000 & 0.025 \\
\hline \multicolumn{9}{|c|}{ Need for attention (IDCP-2) } \\
\hline None & 2.00 & 15.00 & 23.75 & 0.50 & & & & \\
\hline Social distancing & 1.94 & 1.61 & 2.26 & 0.69 & & & & \\
\hline Handwashing & 2.17 & 1.91 & 2.4 & 0.60 & & & & \\
\hline All & 2.17 & 2.11 & 2.227 & 0.69 & 0.72 & 3 & 0.539 & 0.003 \\
\hline \multicolumn{9}{|c|}{ Intimacy avoidance (IDCP-2) } \\
\hline None & 1.62 & 12.0 & 21.00 & 0.51 & & & & \\
\hline Social distancing & 1.86 & 1.50 & 2.22 & 0.75 & & & & \\
\hline Handwashing & 1.42 & 1.18 & 1.68 & 0.57 & & & & \\
\hline All & 1.49 & 1.44 & 1.54 & 0.61 & 2.28 & 3 & 0.078 & 0.010 \\
\hline \multicolumn{9}{|l|}{ Conscientiousness } \\
\hline \multicolumn{9}{|c|}{ Conscientiousness (BFI-2-S) } \\
\hline None & 3.00 & 20.83 & 39.00 & 1.06 & & & & \\
\hline Social distancing & 3.89 & 3.52 & 4.24 & 0.74 & & & & \\
\hline Handwashing & 3.65 & 3.35 & 3.96 & 0.74 & & & & \\
\hline All & 3.79 & 3.73 & 3.84 & 0.72 & 2.74 & 3 & 0.042 & 0.011 \\
\hline \multicolumn{9}{|c|}{ Concern with details (IDCP-2) } \\
\hline None & 1.55 & 10.83 & 20.0 & 0.50 & & & & \\
\hline Social distancing & 2.80 & 2.44 & 3.17 & 0.75 & & & & \\
\hline Handwashing & 2.34 & 1.94 & 2.74 & 0.92 & & & & \\
\hline All & 2.56 & 2.50 & 2.62 & 0.83 & 3.92 & 3 & 0.009 & 0.016 \\
\hline \multicolumn{9}{|c|}{ Thoroughness (IDCP-2) } \\
\hline None & 1.79 & 10.8 & 25.00 & 0.74 & & & & \\
\hline Social distancing & 2.85 & 2.60 & 3.08 & 0.50 & & & & \\
\hline Handwashing & 2.36 & 2.00 & 2.69 & 0.87 & & & & \\
\hline All & 2.66 & 2.60 & 2.71 & 0.72 & 4.40 & 3 & 0.004 & 0.018 \\
\hline
\end{tabular}

$\mathrm{All}=$ people who think the containment measures are important; ANOVA = analysis of variance; BFI-2-S = Big Five Inventory-2 Short; $\mathrm{F}=\mathrm{ANOVA} \mathrm{F}$ statistic; Handwashing = people who think handwashing is important but not social distancing; IDCP-2 = Dimensional Clinical Personality Inventory 2 ; $M=$ mean; $M$ lower = lower bound of confidence interval of the mean; M upper = upper bound of confidence interval of the mean; None = people who don't think the containment measures are important; $\mathrm{p}=$ statistical significance; partial $\eta 2$ : partial eta squared; $\mathrm{SD}=$ standard deviation; Social distancing = people who think social distancing is important but not handwashing.

Groups discriminated from the other groups in the post hoc test are presented in grey. 
measures. Factors related to maladaptive variants of personality traits (i.e., Need for attention [ $p=0.003$ ], Intimacy avoidance $[p=0.010]$, Concern with details $[p<0.016]$, and Thoroughness $[p=0.018]$ ) presented larger group differences in comparison to factors related to healthy personality traits.

\section{Discussion}

We are now living with a pandemic caused by a coronavirus that spreads the COVID-19. Containment measures have been recommended, ${ }^{11-15}$ including social distancing and handwashing. However, several factors can increase or decrease people's engagement with these measures. We aimed to investigate to what extent two personality traits, extroversion and conscientiousness, are associated with engagement with two containment measures (social distancing and handwashing). To achieve this we collected data from a Brazilian sample. The findings corroborate our hypothesis, indicating that extroverted functioning seems to lack engagement with the COVID-19 containment measures. At the same time, a conscientiousness pattern is more cautious in following all the recommendations. Although preliminary, these findings add empirical data to the critical debate on individual behavioral responsibility in co-operating with containment measures to prevent even worse outcomes from this pandemic. ${ }^{17,18}$

The lower scores for extroversion observed in the social distancing group, indicate the challenging task of reducing the social proximity typical of extroverted people, which seemed not to greatly impact their readinesstoengage with hand hygienerecommendations. The difficulty in reducing social proximity is coherent with the typical characteristics of extroversion. ${ }^{20,22}$ Moreover, the factors evaluating maladaptive variations of extroversion, ${ }^{21}$ Need for attention and (negatively) Intimacy avoidance, highlighted the trend of extroverted people to avoid social distancing. These results suggest that pathological levels may bring even more difficulty with engagement with pandemic containment measures.

In a manner that differs from what was observed for the extroversion trait, low conscientiousness scores were presented by people reporting that they did not engage with any of the containment measures. We can hypothesize that an increase in conscientiousness scores is associated with a decrease in the propensity to break safety recommendations for containment of the pandemic. Moreover, engaging with social distancing does not seems to be a problem for people who score high for this trait. These trends are consistent with the conceptualization of the conscientiousness trait. ${ }^{20,22}$ The Concern with details and Thoroughness factors corroborated this trend, even though they relate to maladaptive variations of conscientiousness.

Our results comprise initial evidence on the association between personality traits and engagement with measures for containment of the COVID-19 pandemic. People who score high for extroversion are probably experiencing more difficulty in following the global recommendations to slow down the spread of the COVID-19, especially the social distancing containment measures. In contrast, people who score high for conscientiousness are more likely to find it easy to adhere to the proposed containment measures. The impact of these different experiences in mental health is yet to be known. However, our findings indicate the importance of acknowledging extroversion and conscientiousness traits as relevant to people's engagement with the recommended actions. They are an alert to the need for strategies that promote adherence to containment measures by people high in extroversion, since their difficulty in maintaining social distance can put them at a higher risk of contamination and of acting as transmission vectors. Our results provide data for psychological assessment and intervention during the COVID-19 pandemic.

The methodological limitations of our study must be acknowledged. First, this is a cross-sectional study with a restricted convenience sample, and potential uncontrolled confounding variables, which introduce biases to the findings. Second, we only administered self-report scales and did not employ a multimethod approach. Third, we focused on two containment measures and not on all possible measures recommended in the present pandemic situation.

We hope our findings can contribute to dealing with this grueling time for humanity. Many efforts to minimize the damage of the COVID-19 pandemic are underway. We can only agree with the closing words of Wang et al. ${ }^{3}$ : "Every effort should be given to understand and control the disease, and the time to act is now."

\section{Disclosure}

No conflicts of interest declared concerning the publication of this article.

\section{References}

1. Higemura J, Nakamoto K, Ursano RJ. Responses to the outbreak of novel influenza A (H1N1) in Japan: risk communication and shimaguni konjo. Am J Disaster Med. 2009;4:133-4. 
2. Shigemura J, Tanigawa T, Saito I, Nomura S. Psychological distress in workers at the Fukushima nuclear power plants. JAMA. 2012;308:667-9.

3. Wang C, Horby PW, Hayden FG, Gao GF. A novel coronavirus outbreak of global health concern. Lancet. 2020;395:470-3.

4. Kim JS, Choi JS. Factors influencing emergency nurses' burnout during an outbreak of Middle East respiratory syndrome coronavirus in Korea. Asian Nurs Res. 2016;10:295-9.

5. Bao Y, Sun Y, Meng S, Shi J, Lu L. 2019-nCoV epidemic: address mental health care to empower society. Lancet. 2020;395:e37-8.

6. Duan L, Zhu G. Psychological interventions for people affected by the COVID-19 epidemic. Lancet Psychiatry. 2020;7:300-2.

7. Kang L, Li Y, Hu S, Chen M, Yang C, Yang BX, et al. The mental health of medical workers in Wuhan, China dealing with the 2019 novel coronavirus. Lancet Psychiatry. 2020;7:e14.

8. Shigemura J, Ursano RJ, Morganstein JC, Kurosawa M, Benedek DM. Public responses to the novel 2019 coronavirus (2019-nCoV) in Japan: mental health consequences and target populations. Psychiatry Clin Neurosci. 2020;74:281-2.

9. Yang Y, Li W, Zhang Q, Zhang L, Cheung T, Xiang YT. Mental health services for older adults in China during the COVID-19 outbreak. Lancet Psychiatry. 2020;7:e19.

10. Wang G, Zhang Y, Zhao J, Zhang J, Jiang F. Mitigate the effects of home confinement on children during the COVID-19 outbreak. Lancet. 2020;395:45-7.

11. Kickbusch I, Leung G. Response to the emerging novel coronavirus outbreak. BMJ. 2020;368:m406.

12. Mahase E. China coronavirus: WHO declares international emergency as death toll exceeds 200. BMJ, 2020;368:m408.

13. Wilder-Smith A, Chiew CJ, Lee VJ. Can we contain the COVID-19 outbreak with the same measures as for SARS? Lancet Infect Dis. 2020 Mar 5. pii: S1473-3099(20)30129-8. doi: 10.1016/S14733099(20)30129-8. [Epub ahead of print]

14. Wilder-Smith A, Freedman DO. Isolation, quarantine, social distancing and community containment: pivotal role for old-style public health measures in the novel coronavirus (2019-nCoV) outbreak. J Travel Med. 2020;13:23-7.

15. Xiang YT, Zhao YJ, Liu ZH, Li XH, Zhao N, Cheung T, et al. The COVID-19 outbreak and psychiatric hospitals in China: managing challenges through mental health service reform. Int J Biol Sci. 2020;16:1741-4.

16. World Health Organization. "COVID-19". WHO. 2020 [cited 25 March 2020]. http:// https://www.who.int/docs/default-source/ coronaviruse/transcripts/who-audio-emergencies-coronaviruspress-conference-full-20mar2020.pdf
17. Lunn P, Belton C, Lavin C, McGowan F, Timmons S, Robertson D. Using behavioural science to help fight the coronavirus. ESRI. 2020. [cited 25 March 2020]. https://www.esri.ie/system/files/ publications/WP656.pdf

18. Anderson RM, Heesterbeek $\mathrm{H}$, Klinkenberg $D$, Hollingsworth TD. How will country-based mitigation measures influence the course of the COVID-19 epidemic?. Lancet. 2020;395:931-4.

19. Li JB, Yang A, Dou K, Wang LX, Zhang MC, Lin X. Chinese public's knowledge, perceived severity, and perceived controllability of the COVID-19 and their associations with emotional and behavioural reactions, social participation, and precautionary behaviour: a national survey. PsyArXiv. 2020. [cited 25 March 2020]. https:// doi.org/10.31234/osf.io/5tmsh

20. Saulsman LM, Page AC. The five-factor model and personality disorder empirical literature: a meta-analytic review. Clin Psychol Rev. 2004;23:1055-85.

21. Allik J, Realo A, McCrae RR. Universality of the five-factor model of personality.

22. Soto CJ, John OP. The next Big Five Inventory (BFI-2): developing and assessing a hierarchical model with 15 facets to enhance bandwidth, fidelity, and predictive power. J Pers Soc Psychol. 2017;1:113-7.

23. Santos D, Primi R. Desenvolvimento socioemocional e aprendizado escolar: uma proposta de mensuração para apoiar políticas públicas. Relatório sobre resultados preliminares do projeto de medição de competências socioemocionais no Rio de Janeiro. São Paulo: OCDE, SEEDUC, Instituto Ayrton Senna; 2014.

24. Carvalho LF, Primi R. Technical manual of the Dimensional Clinical Personality Inventory 2 (IDCP-2) and Dimensional Clinical Personality Inventory screening version (IDCP-triagem). São Paulo: Pearson. Forthcoming 2020.

25. Carvalho LF, Sette CP, Capitão CG, Primi R. Propriedades psicométricas da versão revisada da dimensão necessidade de atenção do inventário dimensional clínico da personalidade. Temas Psicol. 2014;22:147:60.

26. Carvalho LD, Souza BD, Primi R. Psychometric properties of the revised conscientiousness dimension of Inventário Dimensional Clínico da Personalidade (IDCP). Trends Psychiatry Psychother. 2014;36:23-31.

\section{Correspondence:}

Lucas de F. Carvalho

Rua Waldemar César da Silveira, 105

Jardim Cura D'Ars (SWIFT)

13045-510 - Campinas, SP - Brazil

E-mail: lucas@labape.com.br 